\title{
INTRODUCING ENHANCED AND INTEGRATED CARE FOR DIABETIC AND TUBERCULOSIS PATIENTS IN FIVE DISTRICTS OF PAKISTAN

A.H.Aamir ${ }^{1}$, N. Safdar, K.L. Ahmed, J.A.Khan, U. Hussain.

${ }^{1}$ Department of Diabetes, Endocrinology and metabolic diseases, Hayatabad medical complex Peshawar, Pakistan.

\section{CONTEXT}

- Dual burden of Diabetes-TB is a serious and growing challenge for the poorly resourced health system of Pakistan

- Pakistan ranks $5^{\text {th }}$ among the highest TB burden countries in the world (WHO Global TB Report)

- The number of diabetics is anticipated to rise to 13.9 million by 2020 in Pakistan and may increase country ranking to 4th in the world (Wild S, etal)

- Limited efforts concerning linking Diabetes and TB care are in place in the government hospitals momentarily

- An integrated and structured screening, referral,
E-mail: drahaamir@gmail.com

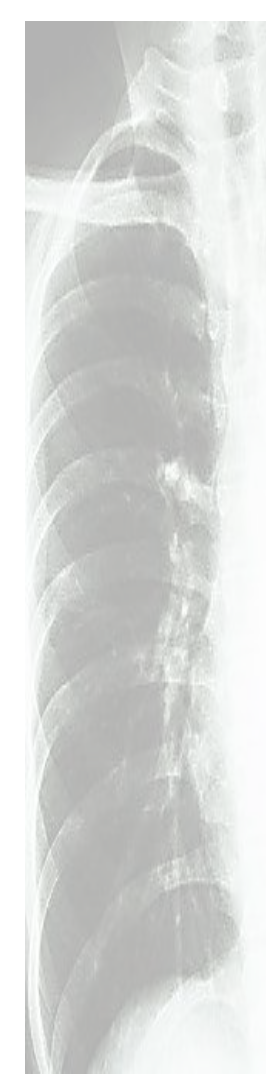

\section{OBJECTIVES}

- Develop operational guideline and tools for integrating diabetic and TB care in routine district health care setting

- Systematic screening of $75 \%$ i.e. 75,000 of 100,000 diabetic and 8,625 of 11,500 TB patients in selected five districts of Pakistan

- Train physicians and paramedics in Diabetic and TB clinics for systemic screening, referral, case management and follow-up

- Organize TB-DM awareness \& screening camps

- Develop a scale-up action plan for DiabetesTB care

\section{METHODOLOGY/KEY ACTIVITIES}

\section{1) Development Phase}

- Develop screening algorithms (Diabetic patients suspected for TB and TB patients suspected for Diabetes)

- Developing care delivery tools (screening, management, registration, follow-up, education/ motivations, etc)

- Developing a joint plan of implementation (Program level, Hospitals level)

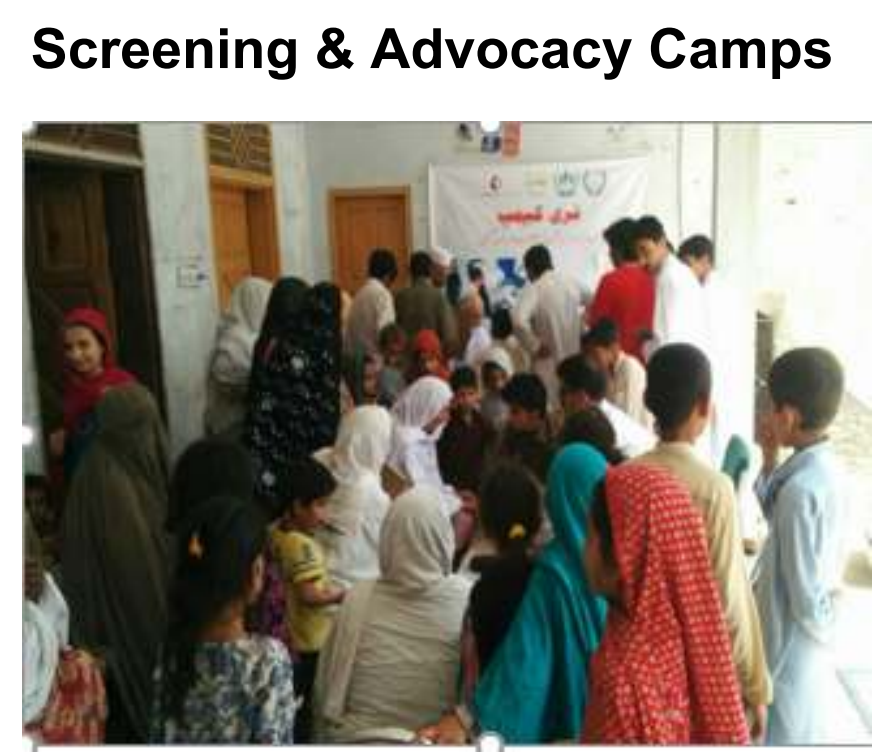

2) Implementation Phase

- Training of care providers both in Diabetic clinic and TB care providers

- Screening (verbal and blood glucose testing) and Registration of cases both at Diabetic clinic (12) and TB clinics (13)

- Outreach TB-DM screening and advocacy camps

- Evaluation of disease outcomes

3) Scale-up Phase

- Develop scale-up plan to involve additional districts and hospitals

\section{RESULTS}

\section{Patients Screened for Diabetes at TB Clinics} (April, 2015 to Sept, 2017)

Patients screened for DM at TB Clinic

\begin{tabular}{c|c|c|c|c|c|c|} 
District & PPBG & RBS & FBG & FBG & Refer to & Registered \\
& screened & + & screened & + & DM & \\
\hline Peshawar & 3761 & 379 & 95 & 21 & 284 & 38 \\
\hline Mardan & 1948 & 150 & 9 & 4 & 134 & 46 \\
\hline Swat & 1939 & 104 & 70 & 49 & 70 & 36 \\
\hline Abbottabad & 1714 & 325 & 130 & 78 & 196 & 13 \\
\hline DIK & 3134 & 198 & 65 & 38 & 95 & 47 \\
\hline Total & 12496 & 1156 & 369 & 190 & 779 & 180 \\
\hline
\end{tabular}

Patients Screened for Tuberculosis at DM Clinics (April, 2015 to Sept, 2017)

\begin{tabular}{|c|c|c|c|c|}
\hline \multirow{2}{*}{ District } & \multicolumn{4}{|c|}{ Patients screened for TB at DM Clinic } \\
\hline & $\begin{array}{c}\text { Screened } \\
\text { for TB }\end{array}$ & $\begin{array}{c}\text { Presumptive } \\
\text { TB }\end{array}$ & Referred & $\begin{array}{c}\text { Diagnosed } \\
\text { with TB }\end{array}$ \\
\hline Peshawar & 37079 & 553 & 542 & 221 \\
\hline Mardan & 7997 & 72 & 69 & 5 \\
\hline Swat & 7647 & 104 & 103 & 20 \\
\hline Abbottabad & 6641 & 97 & 87 & 15 \\
\hline DIK & 7849 & 159 & 127 & 32 \\
\hline Total & 67213 & 985 & 928 & 293 \\
\hline
\end{tabular}

Targets vs Achievements

(April, 2015 to August, 2017)

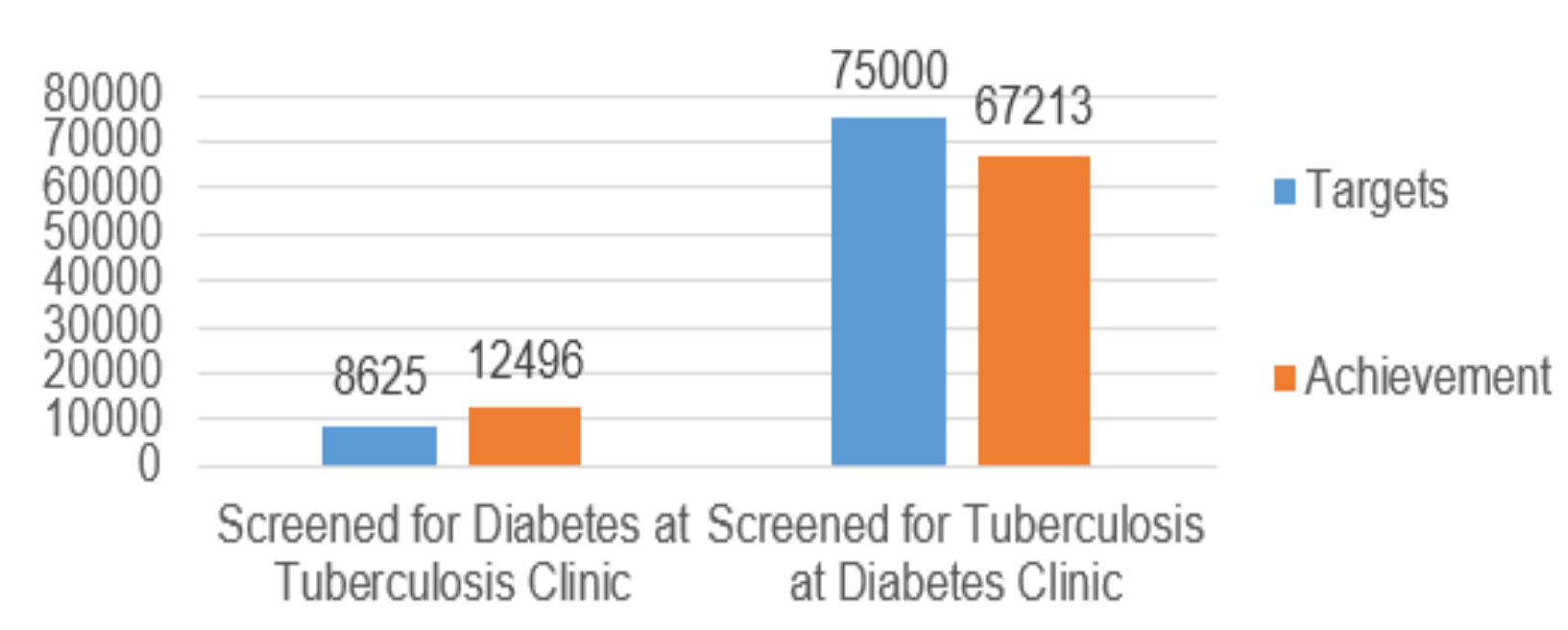

\section{IMPLEMENTATION CHALLENGES}

\section{WAY FORWARD}

- National Dissemination meeting

- Scale up plan to be prepared \& disseminated

- Scale up of intervention has been considered through public sector funding
- Under developed referral system

- No national diabetes program

- Lack of dedicated staff- compromised documentation

- Lack of coordination with private sector

- Not all patients referred from TB clinics are getting registered at Diabetics clinics

- Screening all TB patients for Diabetes at high yield TB clinics is a challenge 